\title{
Vocabulary Learning Strategies of the Advanced Students
}

\author{
Katarzyna Maria Nosidlak \\ School of English, Adam Mickiewicz University, al. Niepodległości 4, 61-874 Poznań, Poland
}

\begin{abstract}
The purpose of this article is to present the results of the research conducted on 102 students of English philology on the Pedagogical University of Cracow, Poland. It focuses on the vocabulary learning strategies used by the advanced students of English seen as the successful language learners. The author of this article tries to discover and systematize the strategies used especially by this group - the group which successfully deals with countless number of new vocabulary items on the daily basis. Precisely, the aim of the following article is to present and analyze the findings of the survey conducted in order to specify which vocabulary learning strategies are used by the advanced students and to discover whether the kind of strategies is related to proficiency. What is more, the author suggests how the data gathered during this research may be helpful when choosing strategies which are presented to students of lower levels. The first part of the paper presents the theoretical background to the topic of vocabulary learning strategies, focusing on their kinds and usage. The following part of the article presents the design of the study i.e. the subjects of the research are described, the research questions are provided and the structure of the questionnaire is outlined. Then the research findings are presented. The issues raised in the research questions are addressed and some teaching implications are offered.
\end{abstract}

Index Terms - vocabulary learning, learning strategies, vocabulary learning strategies, vocabulary sources, vocabulary acquisition, advanced language learners, university students

\section{INTRODUCTION}

Vocabulary acquisition is increasingly viewed as crucial to language acquisition (Uberman, 1998, p.20). It is generally believed that if language structures make up the skeleton of language, then it is vocabulary that provides the vital organ and flesh (Harmer, 1997, p.153). No wonder that the researchers have been constantly trying to discover the most effective ways in which new vocabulary items can be acquired in a quick and pleasant way...

When looking at these findings, one has to remember about the specificity of university education. The university students are supposed to be ready for independent education. What is more, after many years of language learning they for sure developed their personal array of strategies. They are mature users of language, knowing their preferences and learning style. Using advanced students' experience and expertise in the field of vocabulary learning may save a lot of time and effort for their younger and less proficient colleagues.

\section{THEORY OF VocABUlary LEARNING STRATEGIES}

Learning strategies can be used for a variety of purposes. One of these purposes is vocabulary learning. Appreciation of the importance of both these areas (of vocabulary and of learning strategies) has led to considerable research in each, yet the place where they intersect - vocabulary learning strategies - has attracted a noticeable lack of attention (Schmitt, 1997, p.199). Schmitt provides an overview of the rise of importance of this type of strategies and enumerates those few researchers who are interested in this particular topic. He underlines that few individual vocabulary strategies have been researched in any depth, the main exceptions being guessing from context (Huckin, Haynes, and Coady, 1993) and certain mnemonics like the Keyword Method (Pressley, Levin, and Miller, 1982; Pressley et al., 1982a) (in Schmitt, 1997). Although the area of vocabulary learning strategies has not been explored enough, there are some findings which can be used as a scaffolding for further research.

\section{A. The Place of Learning Strategies in Vocabulary Acquisition}

Vocabulary learning can be viewed as a process of sub-tasks (Gu, 2003). A number of different vocabulary learning strategies can be used by learners to complete these tasks. Gu (2003) enumerates, inter alia, guessing the meaning of a word, looking it up in the dictionary, taking notes, rote repetition, using the word actively... Each of these task stages demands metacognitive judgment, choice, and deployment of cognitive strategies for vocabulary learning. And each strategy a learner uses will determine to a large extent how and how well a new word is learned (Gu, 2003).

Research (by Coady (1997), Oxford (1990), Scarella (1994), and Nation (2001) in Mercer, 2008) indicates that vocabulary learning can be enhanced when a student's attention is directed to vocabulary strategies. What is more, many learners use vocabulary learning strategies. Chamot (1987 in Schimtt, 1997) proved in his research that learners 
reported more strategy use for vocabulary learning than for any other learning activity, including oral presentation, listening comprehension, and social communication.

\section{B. A Taxonomy of Vocabulary Learning Strategies}

There have been a number of attempts to develop a taxonomy of vocabulary learning strategies. Below one can find some of the most complete and useful ones.

Gu and Johnson (1996 in Nation, 2001) developed such taxonomy through their extensive research in Chinese classrooms. They provided a list of vocabulary learning strategies, which is based on a division into:

- beliefs about vocabulary learning,

- metacognitive regulation,

- guessing strategies,

- dictionary strategies,

- note-taking strategies,

- memory, rehearsal strategies,

- memory encoding strategies,

- activation strategies.

$\mathrm{Gu}$ (2003), in his more recent article, names two important factors which can be used for the division of vocabulary learning strategies, namely task and person. Task-dependent vocabulary learning strategies are those which are applied by students depending on a kind of sub-task. Among those strategies, Gu (2003) lists different strategies used by students, for example, guessing, dictionary strategies, note-taking, rote rehearsal... What is more, he also states that there are four main fields of interest when it comes to processing of a word, namely memory, form, meaning and use. He also underlines the importance of context. Strategies belonging to each of this filed will be now discussed more precisely...

Memory strategies, or mnemonics, have received by far the most attention. Gu (2003) even claims that this interest has turned into classic case of overkill. It is believed that mnemonic devices work well because they boost our memory and, as we all know, vocabulary learning is essentially a memory issue (Gu, 2003). Despite all the praise, mnemonics have also their shortcomings which are enumerated by Gu (2003):

- mnemonic devices mainly aim for the retention of paired-associates. And the vocabulary of an L2 is far more than a collection of L1-L2 word pairs (Richards, 1976);

- mnemonic approach to vocabulary underlines one-to-one relationship between form and meaning, forgetting about multiple dimensions of meanings;

Generally speaking, learners of a foreign language should be explicitly warned that mnemonic devices are only meant to complement rather than replace other approaches to vocabulary learning (Cohen, 1987). As Carter (1987, p. 188) rightly contends, too great a focus on learning vocabulary as discrete items may well lead to neglect of the skill aspect of vocabulary in natural discourse (ibid).

Form is another field of interest when it comes to vocabulary. What is crucial here is the usage of so called word formation strategy.

Then comes focus on meaning and a theory related to this particular field, namely the concept of semantic networks. Semantic network is understood as the mental organization of the lexicon whereby words and concepts that share some meaning are related both hierarchically and laterally (Gleason and Ratner, 2005). There are some strategies which are based on this idea of a network of semantic associations.

The last but not least field of interest mentioned by Gu (2003) is context. The previous strategies are focused on various types of vocabulary encoding and treat vocabulary as a collection of discrete items. However, while these strategies constitute a considerable part of the vocabulary learning process, a vocabulary development agenda that includes mainly these strategies might well lead to a dangerously simplistic conception of vocabulary amongst undiscerning beginners (ibid). That is why it is important to look at vocabulary more holistically. Arnaud and Savignon (1997, in $\mathrm{Gu}, 2003)$ note two kinds of strategies associated with complex lexical units: awareness strategies and retention strategies.

The second basic kind of division mentioned earlier includes person-dependent vocabulary learning strategies. Whether and how a learner evaluates the task requirement and whether and how a cognitive strategy is deployed are often dependent more on the learner than on the task ( $\mathrm{Gu}, 2003)$. It is obvious that there are individual differences which influence the choice of strategies, for example motivation, self-efficacy, gender, learning background, and learning styles.

Then, Schmitt (1997) categorized vocabulary learning strategies into six groups with 58 individual strategies in total. His taxonomy is based on Oxford's division into social (SOC), memory (MEM), cognitive (COG), meta-cognitive (MET), compensation (COM), and affective.

To sum up, one can easily see that the taxonomies of vocabulary learning strategies draw on the findings from the field of learner's strategy use, understood more broadly and concerning all aspects of language, not only vocabulary. Still, Brown and Payne (1994 in Hatch and Brown, 1995) offered a taxonomy of vocabulary learning strategies which successfully joins both division into numerous strategy kinds, and which concerns the process of vocabulary acquisition. The author of this article wants to present their taxonomy as the summary of what has been said before... 
The vocabulary strategies fall into five essential steps:

1) Having sources for encountering new words,

2) Getting a clear image, either visual or auditory or both, for the form of the new words,

3) Learning the meaning of words,

4) Making a strong memory connection between the forms and meanings of the words,

5) Using the words.

Each step is characterised by the use of specific vocabulary learning strategies. The first stage involves encountering new words. As far as incidental learning of vocabulary goes, this step is obviously the most vital. Because the incidental learning of vocabulary must occur if second language learners are to approach a vocabulary that compares with that of native speakers, this step is crucial (Hatch and Brown, 1995, p. 374). The number of words that passes this step may vary depending on the natural learner interest, motivation, need, context and level of proficiency. The strategies used during this stage involve e.g.:

$\sqrt{ }$ Reading books;

$\sqrt{ }$ Listening to $\mathrm{TV}$ and radio;

$\sqrt{ }$ Reading newspapers and magazines;

$\sqrt{ }$ Talking with other users of the language;

$\sqrt{ }$ Using traditional materials (textbooks, word lists, dictionaries)...

The second step essential to vocabulary learning appears to be the getting of a clear image - visual or auditory or both - of the form of the vocabulary item. Strategies here include, among others:

$\sqrt{ }$ Forming associations (e.g. between L1 and L2 words, between L2and L2 words, between L2 and L3 words);

$\sqrt{ }$ Using sound symbols;

$\sqrt{ }$ Using phonological cues, stress...

The next stage, the one which is the one most often associated with vocabulary learning, is getting the word meaning. Although the depth of definition needed may vary and the sources from which meaning can be extracted may be quite different, all learners must get the meaning of words in some manner, or the words can never be considered truly learned (Hatch and Brown, 1995, p. 386). According to Hatch and Brown (1995), one can include here for example:

$\sqrt{ }$ Asking others about the word meaning (other students, native speakers, teachers);

$\sqrt{ }$ Mind mapping;

$\sqrt{ }$ Using context (situational, discourse, specific context e.g. a text);

$\sqrt{ }$ Using dictionaries...

Once the meaning and form of a word is clear, both aspects must be consolidated in memory. As it has been already said, this group of strategies (called mnemonics) is especially widely used by second language learners. Hatch and Brown (1995) quote here Oxford (1990) and her division of memory strategies, which has been already discussed. Which method learners use for this step does not seem to be as crucial as they do it. The more words learners can get through this step, the more words they will know overall.

The final step in vocabulary acquisition involves using the word. This step is necessary not only to in order to boost students' receptive knowledge, but also in order to increase their self-confidence and to give them opportunity o test their knowledge of collocations, syntactic restrictions and register appropriateness. The strategies used here should include both testing, but also stress-free activities allowing for the using of a word without undesired consequences i.e bad marks (Hatch and Brown, 1995, p. 392).

Summing up, although there is a broad range of activities, strategies, or techniques that individuals use at each step, the necessity of the steps seems more constant. Learners need all five in order to have a full knowledge of the words they want to learn (ibid).

Once the theoretical backgrounds of this article have been discussed, the author is going to focus on the research which she has conducted in the field of vocabulary learning strategies.

\section{RESEARCH DESIGN}

The subjects of the survey were the students of English philology on the Pedagogical University of Cracow, Poland. All of them attended full-time studies. Out of 102 students, 48 were the students of the first year of B.A. studies, 31 of the third year of B.A. studies, and 22 represent the second year of M.A. studies. These students were given a questionnaire designed in order to find out the answers to the following research questions:

1. Which vocabulary learning strategies do students use?

2. Do students on different levels differ in the kind of vocabulary learning strategies they claim to use?

The questionnaire was developed on the basis of the taxonomy of learning strategies by Oxford (1990) and on five steps in learning vocabulary described by Hatch and Brown (1995).

The questionnaire consisted of 13 questions. First question was open and involved giving a definition of learning strategies, the rest was half-open - there were options provided, but the students were also given the freedom of adding their own options. The next three questions concerned the source of new vocabulary items, whereas in the question number 7 students were required to specify the way in which they discover the meaning of new vocabulary items. Then 
the questionnaire focused on memory strategies in relation to spelling, pronunciation and meaning (questions 5, 6, 8), and moved to affective (question 9), cognitive (question 10), compensation (question 11), metacognitive (question 12) and social (question 13) strategies used for vocabulary acquisition.

The language used in the questionnaire was subjects' mother tongue (Polish). This was an intentional move ensuring the total students' understanding of both questions and provided options. What is more, the questionnaire was written in a clear and simple manner in order to exclude the possibility of misunderstanding.

\section{RESEARCH FINDINGS}

Before presenting the analysis of the data gathered during the research, it should be emphasized that all the students who took part in the research were then studying to become English teachers. Thus they constitute a perfect group for this type of research - as motivated and dedicated students of English, they, for sure, gained the most from the strategy training they received. That is why, the data which was gathered and the conclusions which can be drawn on its basis will be more useful for the teachers of the less advance students for whom the level obtained by the subjects of this research is still the thing of the future...

THE USE OF VOCABULARY LEARNING STRATEGIES IN THE CASE OF THE ADVANCED STUDENTS OF ENGLISH.

The data gathered during the research enables the author of this article to state which types of vocabulary learning strategies are used by students on different levels of proficiency.

After the thorough analysis, the following conclusions may be drawn:

$\sqrt{ }$ The advanced students use diverse and multiple sources of new words.

First of all, the students were asked about their sources of new vocabulary items. Without looking for the opportunity to encounter new words, students cannot broaden their personal array of vocabulary effectively. Therefore, the author of this thesis treats the ways in which students find new words as vocabulary learning strategies.

On average, the students declared that they use over 6 different vocabulary sources. Therefore, it can be stated that advanced students of English make use of multiple sources when broadening their personal mental lexicon. Obviously, new vocabulary items can be spotted in a wide range of contexts. It has been proved (Takac, 2009) that the role of the vocabulary context in initial steps of learning is limited, but its significance grows as the learner's proficiency expands. The relationship between the number of vocabulary sources and the level of proficiency may be easily explained - a learner must be provided with comprehensible input in order to acquire language; therefore, more advance students when encountering a variety of vocabulary sources on the daily basis (TV, songs etc.) use a lot of them as their linguistic knowledge enables them to make use of the majority of this sources.

\section{$\sqrt{ }$ The Internet as the most popular source of new vocabulary.}

Living in the era of the World Wide Web, one cannot be surprised finding out that the Internet turned out to be the most popular source of new words. When it comes to modern technologies, there were also some students who wrote about computer games as a source of vocabulary.

These results are especially important for contemporary teachers - modern technologies are becoming more and more popular, and thus they must have their place in each language classroom. Students must be able to use the Internet for educational purposes, including vocabulary learning, so they have to be trained to do it properly. Without this type of course, the computer may become the enemy, whereas it should be students' best friend. This type of training would allow students to develop a group of vocabulary learning strategies useful during e-learning sessions. Technology-based learning, which constitutes learning via electronic technologies, including the Internet, holds the promise of substantially transforming the way learning takes place because of its numerous advantages, e.g. its great accessibility, low costs, game-like character or providing students with hands-on opportunities to learn (Koller, Harvey, Magnotta, 2010, p. 5).

\section{$\sqrt{ }$ Traditional sources of vocabulary still popular among advanced students of English.}

On the other hand, the students still enumerate their teachers and lecturers among the most popular sources of vocabulary knowledge. Also other traditional sources (like English books, dictionaries, vocabulary books and materials and TV/radio) are still widely used. On the contrary, the least attractive options included Native speakers and Other students. Interestingly, these two options got especially low percentage in the case of the first year students. This may result from the fact that the students of the first year simply know each other less, and thus they cooperate less often. In the case of the native speakers seen as vocabulary source, this disproportion can suggest that the students of the first year may have less opportunities to meet natives in comparison to their older colleagues. What is more, the low popularity of this option may also be seen as the reflection of Polish mindset. Poland has extremely high score when it comes to uncertainty avoidance on Hofstede's scale. Polish people usually think that what is different is dangerous. That is why, Polish students may be reluctant to communicate with foreigners at the beginning of their linguistic education. Changing this state of affairs would involve a difficult campaign to get rid of stereotypical ways of thinking, which are very often subconscious. The first step in this battle should consist in realising these personal convictions.

As it can be easily seen from the data presented above, advanced students have to be provided with multiple sources of vocabulary because, first of all, they use a lot of them, and what is more, they may have different needs in this respect. A contemporary teacher has to remember about the educational challenges issued by the modern technologies 
and try to implement these new vocabulary sources during his/her lessons. Still, the traditional and well-tried sources of vocabulary cannot be forgotten. A modern vocabulary teaching session should constitute a well-balanced mixture of the old and the new.

$\sqrt{ }$ The students, regardless of their level of proficiency, use similar, but diversified strategies to get the meaning of a word.

Also when it comes to the strategies used to get the meaning of a new word, the students use miscellaneous strategies depending on the learning context. The most popular strategy involved checking the meaning in the dictionary. Then the next choices included more time-consuming strategies, namely using context and using personal knowledge concerning word parts. The popularity of dictionaries can easily be explained - finding the meaning in a dictionary is the easiest and the quickest way to discover the meaning. No wonder, that busy and sometimes overworked university students turn to this method. Still, one has to remember that the more effort the student puts in the discovery of a word meaning and the more time he/she spends dealing and having contact with a new word, the greater the chance that the word will be memorized. Thus, using the dictionary is not always the best option.

Another interesting point is that the students are quite reluctant to ask others for help in order to discover the meaning of a vocabulary item - option I ask somebody who is better informed or more competent was one of the least popular for all three groups. This may be once more the result of Polish mindset. According to Hofstede's social dimensions, Poland is a masculine country in which people are ego-oriented and individualistic. Asking others for help may be seen as face threatening. A lot of Poles can be characterized as overachievers. In our culture it is the best student who sets the norms, thus it is not profitable to admit that somebody can be better informed or more competent. So here strategy training would include changing national stereotypes - students should know that asking for help is not a shame. Teachers should also show their students that they themselves are not omniscient and that learning from others can be a very effective way of self-development.

$\sqrt{ }$ Students on the higher levels of proficiency use fewer and fewer kinds of different strategies, but they use similar strategies.

When comparing the number of different strategies kinds used by the students on different levels of proficiency, one general trend is visible regardless of the subcategory. It is visible that students of the higher levels of proficiency use fewer kinds of vocabulary learning strategies when compared to their colleagues on lower levels.

There are two possible explanations for this state of affairs:

- more advanced students need a given group of strategies less often, thus they need fewer kinds of strategies from this group.

This may be related to the growing level of proficiency - the students know the language better and that is why they do not need as many kinds of strategies as they used to.

- more advanced students successfully eliminate strategies which are not effective and they are left with the best working ones.

What is also important, when talking about teaching implications, is that the advanced students use very similar kinds of strategies, regardless of the subcategory. One has to remember that the subjects of this research are all successful language learners who worked their way through piles of vocabulary lists and who successfully acquired a lot of them. Therefore, one can assume that the strategies which are popular and still used by the advanced students are the ones which are the most effective from a given category and therefore, they should be presented to the students of the lower levels at first. Having in mind the above mentioned conclusions, the author of this thesis is going to look at different types of vocabulary learning strategies and name the ones which work the best. It can be treated as advice for the teachers of the lower levels who would like to start their strategy training with implementing the strategies which will probably be their students' favourites in the future.

- Memory vocabulary learning strategies used for memorising the spelling and pronunciation of a new vocabulary item.

The most popular kinds of learning strategies for memorizing spelling and pronunciation included those consisting in creating mental linkages, using imagination and mechanical repetition/rewriting. Having this in mind, students should be encouraged to try to find a link between the spelling and their knowledge/pronunciation of a word, and to rewrite a given word many times.

- Memory vocabulary learning strategies used for memorising the meaning of a new vocabulary item.

Once more creating mental linkages (e.g. Polish/English associations) and using mechanical strategies turned out to be the most effective. Additionally, using context_seems to be helpful for the majority when it comes to vocabulary memorisation. Thus, students may be asked to write sentences, paragraphs or texts with new words.

What is also interesting when it comes to this type of strategies is that the students use quite a lot of different memory strategies for memorizing meaning, especially when compared to the strategies used for memorising spelling and pronunciation. This tendency is visible for all three groups which took part in the research. This may suggest that the meaning of a word is the most problematic aspect for memorising (so the process of meaning memorisation must be facilitated by the greater number of different memory strategies). Therefore, teachers should help their students in this area especially, by providing them with thorough and well-organised strategy training.

- Affective strategies. 
The data may suggest that with the passing time students either get used to the stress of perspective vocabulary testing, or, as it has been already stated, they know better which strategies work for them. Advanced students of English know how to handle negative emotions and know how to motivate themselves. Using this knowledge, the teachers may advise less advanced students to listen to music, try to think positively, reward themselves and to use checklists in order to organise work. As one can easily see, the most popular affective strategies include those used for lowering anxiety, those for encouraging yourself and the ones consisting in taking your emotional temperature. So all kinds of affective strategies included by Oxford in her taxonomy are useful and should be presented to students during strategy training.

- Cognitive strategies.

Cognitive strategies constitute yet another subcategory of vocabulary learning strategies where one can observe decrease in the number which goes together with the raising level of proficiency. The most effective vocabulary strategies include unsurprisingly creating structure for input and output (underlining, highlighting) and practicing (systematic repetition).

\section{- Metacognitive strategies.}

The biggest decline in the number of kinds was observed for metacognitive strategies. The difference was quite significant. Still, even for the last group, the number of strategy kinds is quite big when compared to other strategies. So, one can assume that these strategies are quite useful for students. When it comes to the effectively, the most useful metacognitive vocabulary strategies are mostly the ones used for planning learning process. Thus, teachers cannot forget about this aspect during strategy training.

The constant drop in the number of kinds of strategies was not observed in the case of compensation and social strategies. The explanation of this fact and some additional interesting observations made in this field are presented below.

\section{- Compensation strategies.}

The students from all groups use very similar compensation strategies, and, what is interesting, they use quite a lot of different kinds of them. One cannot observe any significant decline in this field. It suggests that students on all levels of proficiency, including very advanced ones, have some problems with vocabulary use, and all need compensation strategies to deal with these problems. On the other hand, the big diversity and popularity of different compensation strategies may suggest just the opposite - the students do not use them often, as they are still testing the ones which work for them. Still, the ones which can be presented to less advanced students as the most useful include guessing intelligently (using both linguistic and non-linguistic features), and avoiding, both problematic topics, and vocabulary items (e.g. using less precise items or synonyms instead). Teachers should remember about the second type of strategies when teaching vocabulary - the data suggests that students often try to choose topics which are safe for them, thus it is the job of the teacher to spot the problematic areas and help students to develop vocabulary from a given field.

\section{- Social strategies.}

The data gathered in the field of social vocabulary strategies suggests that students use a wide collection of social strategies when learning new vocabulary items. Another interesting point is that, in contrast to other groups, the fifth year students rarely cooperate with other students in order to develop their vocabulary. It may mean that with passing time and growing experience, students become more independent and self-sufficient. Thus, when working with less advanced and younger students, teachers should assist them more in the case of vocabulary development, but at the same time should help them to develop autonomy in this field.

Additionally, it has been observed that cognitive vocabulary learning strategies are the most diversified in the case of the advanced users of English. Then compensation and metacognitive strategies followed. On the other hand, affective vocabulary strategies are the least diversified.

As it has been already stated, it may suggest that the students simply need a given group of strategies (cognitive) more than another, and thus they use a wider array of strategies from this group. On the other hand, one can also assume that the students may use these strategies rarely and that is why they do not know which of them are the most effective. Having these two possibilities in mind, a teacher cannot forget about any group of strategies when training his/her students. It is the job of a teacher to make students of lower levels familiar with as many strategies as possible. Knowing a bigger array of learning strategies, students will be able to choose their personal strategies more effectively. Still, the data gathered during this research may be helpful when choosing strategies which are presented to students of lower levels. Using advanced students' experience and expertise in the field of vocabulary learning may save a lot of time and effort for their younger and less proficient colleagues.

\section{CONCLUSIONS}

The results of the research which has been presented in this article indicate that advanced students use similar kind of vocabulary learning strategies when learning new vocabulary items. Then it has been shown that, together with the growing level of proficiency, students use less and less kinds of strategies. The strategies which are still used by the advanced students (treated as the successful ones) may be considered to be the most effective. 


\section{REFERENCES}

[1] Gleason, J.B., Ratner, N.B. (2005). Psycholinguistics. Fort Worth: Harcourt Brace College Publishers.

[2] Gu, P.Y. (2003). Vocabulary Learning in a Second Language: Person, Task, Context and Strategies. Teaching English as a Second or Foreign Language. Vol.7. No.2. http://tesl-ej.org/ej26/a4.html (accessed: 17.05.2010).

[3] Harmer, J. (1997). The practice of English Language Teaching. New Edition. Harlow: Longman.

[4] Hatch, E., Brown, C. (1995). Vocabulary, Semantics, and Language Education. New York: Cambridge University Press.

[5] Hofstede, G.J., Pedersen, P.B., Hofstede, G. (2002). Exploring Culture: Examples, Stories and Synthetic Cultures. London: Intercultural Press. http://www.tesl-ej.org/wordpress/issues/volume7/ej26/ej26a4/ (accessed: 17.05.2010.).

[6] Koller, V., Harvey, S., Magnotta, M. (2010). Technology Based Learning Strategies. Prepared for U.S. Department of Labor Employment and Training Administration. English Teaching Forum 43(2): 24-35.

[7] Nation, I.S.P. (2001). Learning Vocabulary in Another Language. Cambridge: Cambridge University Press.

[8] Oxford, R. (1990). Language Learning Strategies. Boston: Heinle \& Heinle Publishers.

[9] Schmitt N. (1997). Vocabulary Learning Strategies. In Schmitt, N., McCarthy, M. (Ed.), Vocabulary: Description, Acquisition and Pedagogy (pp.197-227). Cambridge: Cambridge Language Teaching Library.

[10] Takač, V.P. (2009). Vocabulary Learning Strategies and Foreign Language Acquisition. Clevdon: Multilingual Matters.

[11] Uberman, A. (1998). "The Use of Games for Vocabulary Presentation and Revision." English Teaching Forum 36(1): 20-27.

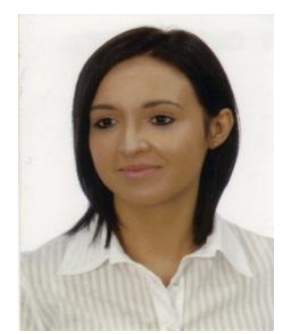

Katarzyna Maria Nosidlak (b. 1986) is currently a Ph.D. student at Adam Mickiewicz University in Poznań, Poland. She studied English philology and received her BA and MA from The Pedagogical University of Cracow. She chose teaching specialization and both her theses dealt with the topic of vocabulary teaching and learning. Apart from vocabulary, her professional interests include the issues of intercultural communication and identity formation in L2 learning. She shares her passion for English with her students at Tadeusz Kościuszko High School in Myślenice, Polska, where she has been working since 2011. Before that, she worked as an English teacher at John Paul II Junior High School in Myślenice (2010-2011) and at the College of Economy, Tourism and Social Sciences in Kielce (2010-2011). 